\title{
Different presentation types of primary Brucella epididimo-orchitis
}

\author{
Huseyin Aydemir ${ }^{1}$, Gokcen Budak ${ }^{2}$, Salih Budak ${ }^{3}$, Orcun Celik ${ }^{3}$, Okan Yalbuzdag ${ }^{3}$, İbrahim Keles ${ }^{4}$ \\ ${ }^{1}$ Department of Urology, Ministry of Health Sakarya Teaching and Research Hospital, Sakarya, Turkey; \\ 2 Department of Infectious Disease Clinic, Tire State Hospital, Sakarya, Turkey; \\ ${ }^{3}$ Tepecik Educational and Research Hospital, Department of Urology, Izmir, Turkey; \\ ${ }^{4}$ Department of Urology, School of Medicine, Afyon Kocatepe University, Afyonkarahisar, Turkey.
}

\begin{abstract}
Summary Brucellosis is a zoonotic disease that involved genitourinary system in $2-20 \%$ and most commonly cause single sided epididymo-orchitis. In our country Brucella is an endemic disease and causes serious and different diagnosis of acute scrotum and epididymoorchitis. In this paper six cases of epididymo-orchitis cases which were resistant to classical treatment were discussed according to clinical and laboratory findings.

We describe different types of presentation of Brucella epididymoorchitis with diagnosis and treatment modalities.
\end{abstract}

KEY WORDS: Brucellosis; Testis; Epididymo-orchitis; Acute scrotum; Infection.

Submittec 5 November 2014; Accepted 28 January 2015

\section{INTRODUCTION}

Brucellosis is spread to humans by infected or contaminated animals and less than sufficiently pasteurized milk and milk products $(1,2)$. Brucellosis can infect many organs and present with different clinical symptoms (3). Brucellosis infects genitourinary system in 2-20\% and most commonly causes single sided epididymo-orchitis (3). Brucella epididymoorchitis (BEO) generally causes acute clinical symptoms (78\%) (3-5). Differential diagnosis of the disease with other emergency urological conditions causing acute scrotum (testicular torsion, testicular tumors, etc.) must be conducted precisely to prevent consequences of surgery.

This paper is aimed to describe differential diagnosis of epididymo-orchitis cases that are resistant to classical treatment or recurrent considering diagnosis and treatment of Brucellosis that still maintains its importance. It also calls attention to different clinical pictures of Brucella epididymoorchitis.

\section{Case reports}

Case 1 (unsuccessful treatment)

A 42 years old male patient with right testicular pain, edema and fever started 2 months before was treated withoute success for recurrent orchitis in another center.
Patient developed joint and muscle pain lately. At physical examination, body temperature was $37.2^{\circ} \mathrm{C}$, swelling on right testicle with extensive tenderness was present, epididymis was hard, scrotum was erythematous and local temperature increased. Examination of other systems was normal. Scrotal color Doppler ultrasonography reported findings consistent with right epididymo-orchitis. Laboratory findings included leucocytes $8700 / \mathrm{mm}^{3}$, sedimentation rate $27 \mathrm{~mm} / \mathrm{h}$, CRP $30 \mathrm{mg} / \mathrm{L}$ and tube agglutination test positive at $1 / 160$ titers. There was no growth in blood cultures. Patient was treated with rifampicin $600 \mathrm{mg} /$ day, doxycycline $200 \mathrm{mg} /$ day and anti-inflammatory treatment for 6 weeks. Symptoms were regressed after first week of treatment. There was no recurrence on the follow up.

\section{Case 2 (septicemia)}

A 63 year old male patient working with farm animals, presented with fever, night sweating and joint pain for 15 days For the last 2 days he had dysuria, swelling in the right testicle and pain. Physical examination showed $37.8^{\circ} \mathrm{C}$ body temperature, right epididymis very tender and swelling of the testicle, local erythema of the scrotum with temperature increase. Physical examination of other systems was normal. Laboratory results showed leucocyte count $13500 / \mathrm{mm}^{3}$, sedimentation rate 67 $\mathrm{mm} / \mathrm{h}$, CRP $70 \mathrm{mg} / \mathrm{L}$, Brucella tube agglutination test positive for 1/640 titer. Brucella spp. growth was documented in blood cultures. Whereas there was no growth in urine culture. Patient's treatment was planned for 6 weeks with rifampicin $600 \mathrm{mg} /$ day, doxycycline 200 $\mathrm{mg}$ /day and anti-inflammatory treatment but in the second week of his treatment testicular pain was not regressed and patient continued to have frequent fever $\left(38^{\circ} \mathrm{C}\right)$. One g/day streptomycin IM was added to treatment for two weeks and treatment was finished up to 6 weeks. After addition of streptomycin on the $3^{\text {rd }}$ day of treatment patient complaints were relieved dramatically. There was no relapse in 18 months follow up.

\section{Case 3 (acute scrotum, septicemia)}

A 27 year old male farmer presented with acute left testicular pain, fever, shivering, nausea and vomiting start- 
ed one day before. At physical examination his body temperature was $38.7^{\circ} \mathrm{C}$ and blood pressure was 90/60 $\mathrm{mmHg}$, he had minimal swelling of left testis, severe tenderness whereas examination of other systems was normal. Laboratory findings showed leucocyte count $21000 / \mathrm{mm}^{3}$, sedimentation rate $50 \mathrm{~mm} / \mathrm{h}, \mathrm{CRP} 77 \mathrm{mg} / \mathrm{L}$. Scrotal color Doppler ultrasonography revealed finding of left epididymo-orchitis. Patient was hospitalized, monitored and treated with $2 \mathrm{~g} /$ day ceftriaxone. On the $3^{\text {rd }}$ day of treatment, symptoms and vital findings were not recovered enough, left testicular edema increased dramatically and erythema and edema involved the left side of scrotum. Brucella was suspected and Coombs test for Brucella was positive, tube agglutination test was positive for 1/320 titer. In blood culture Brucella spp. growth was observed. Patient was treated with rifampicin $600 \mathrm{mg} /$ day, doxicycline $200 \mathrm{mg} /$ day and streptomycin $1 \mathrm{gr} / \mathrm{day} \mathrm{IM}$. Vital findings were normalized after the $2^{\text {nd }}$ day of treatment. Testicular findings recessed after 2 weeks. Patient's treatment was completed in 6 weeks (streptomycin at $15^{\text {th }}$ day). Patient did not have any recurrence orchitis but due to recurrent arteritis patient was transferred to specialized clinic.

\section{Case 4 (nonspecific epididmoorchitis)}

A 50 years old male patient presented with dysuria and right testicular pain for 6 weeks. At physical examination tenderness of right testicular and inguinal canal was present, vital findings and other systems examination was normal. In laboratory findings leucocyte count was $4500 / \mathrm{mm}^{3}$, sedimentation rate was $12 \mathrm{~mm} / \mathrm{h}$ and CRP was $9 \mathrm{mg} / \mathrm{L}$. Scrotal color Doppler ultrasonography showed findings consistent with right epididymo-orchitis. Patient was treated with ciprofloxacin $100 \mathrm{mg} /$ day. At the 4th day of treatment patient presented again with high fever and swelling of right testicle. Physical examination revealed swelling of right testicle, erythema and temperature increase at the right side of the scrotum. His body temperature was $38.2^{\circ} \mathrm{C}$. Patient detailed history revealed that he was treated for Brucellosis 6 months prior. Brucellosis Coombs test was positive and tube agglutination test was positive for 1/160 titer. There was no growth in blood and urine cultures. Patient was treated with rifampicin $600 \mathrm{mg} /$ day, doxycycline $200 \mathrm{mg} /$ day and anti-inflammatory drugs for 6 weeks. His symptoms were diminished after the first week of treatment. There was no recurrence in 6 months follow up of the patient.

\section{Case 5 (bilateral epididymoorchitis)}

A 22 years old male patient presenting with long lasting bilateral testicular pain. Physical examination showed minimal tenderness of both testicles, vital findings and other system examination were normal. Laboratory findings showed no specific findings in urinary analysis, leucocyte count $4100 / \mathrm{mm}^{3}$, sedimentation rate $8 \mathrm{~mm} / \mathrm{h}$, and CRP $6 \mathrm{mg} / \mathrm{L}$. Scrotal color Doppler ultrasonography revealed bilateral testicular increased blood flow. Patient's family was treated for Brucellosis, so Brucellosis panel was studied. Rose Bengal test was positive and tube agglutination test was positive for 1/160 titer. There was no growth in blood or urine culture. Patient was treated with rifampicin $600 \mathrm{mg} /$ day, doxycycline $200 \mathrm{mg} /$ day and anti- inflammatory drugs for 6 weeks. Patient's symptoms were decreased after the $2^{\text {nd }}$ week of the treatment. There was no recurrence in the 3 month follow up of the patient.

\section{Case 6 (testicular tumor suspicion)}

A 30 years old male patient presented to the urology clinic with a left testicular painful mass. Physical examination revealed left testicular stiffness at palpation. Examination of other system was normal. There was no significant clinical or family history. Laboratory findings

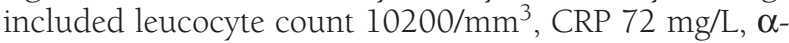
feto protein (AFP) 1.8 (<13.4), BHCG < 1.2. Emergency scrotal ultrasonographyshowed an hypodense $31.8 \mathrm{~mm}$ solid mass of left testicle. After a preliminary diagnosis of seminoma, magnetic resonance imaging (RMI) was scheduled that demonstrated unclear demarcation of the mass with heterogeneous pattern that was reported as consistent with epididymo-orchitis (Figure 1).

Brucella tube agglutination test was positive for $1 / 250$ titer. There was no growth in blood culture. Patient was treated with rifampicin $600 \mathrm{mg} /$ day and doxycycline 200 $\mathrm{mg} /$ day. Pain and swelling regressed and scrotal ultrasonography 2 week after treatment showed dramatic regression. Ultrasonography conducted 3 months later showed further decrease of mass size and at 1 year follow up ultrasonography findings were normal. There was no recurrence at 2 years follow up.

\section{Figure 1.}

Left testicular heterogeneous mass, consistent with epididymoorchitis.

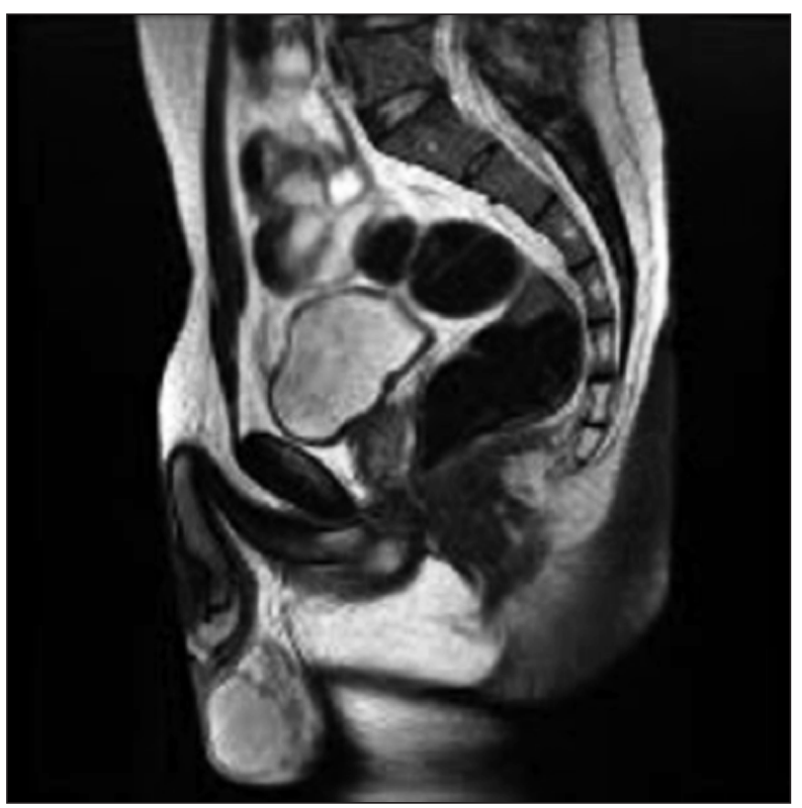

\section{Discussion}

Brucellosis is very rare in developed countries. But it is an endemic zoonotic disease in the Mediterranean basin and Middle East (2). Turkey is in the Brucellosis endemic region and its incidence is 2-6\% (6). In systemic brucellosis, epididymo-orchitis is most commonly seen as unilateral $(3,6,7)$. In a study of 12 cases with genitourinary 
complications due to Brucellosis, 10 cases presented with epididymoorchitis (5). In the same study the ten BEO patients were compared with 15 non-specific epididymoorchitis (EO) cases and BEO was characterized by long-lasting clinical presentation, history of unpasteurized milk consumption, lower urinary system symptoms, normal urinary analysis and frequent leukocytosis (5).

Some tests are required for the diagnosis of brucellosis, in addition to patient history and physical examination (rose bengal, tube agglutination, Coombs test, blood culture). Values of tube test higher of 1/160 titer and blood culture positivity are important for diagnosis (8).

Delayed diagnosis and treatment, can lead to various complications (e.g., testicular abscess, atrophy, necrosis and infertility) (9). It is very difficult to distinguish BEO from non-specific EO (10). Detailed history from the patient is important for diagnosis in case of EO unresponsive to conventional therapy, that should bring to mind brucella EO.

Acute epididymo-orchitis is a frequent disease in urology clinic and one of the causes of acute scrotum.

Differential diagnosis of acute scrotum includes testicular torsion, testicular tumors, appendicular testicular torsion and testicular trauma. Diagnosis of torsion and tumor are crucial because they require fast treatment, so futher radiological tests must be considered. In our $6^{\text {th }}$ case, even though ultrasonography diagnosis was consistent with a testicular tumor MRI results demonstrated epididymoorchitis. Tumor markers in the normal range and tube agglutination test consistent with Brucellosis helped the clinical diagnosis. In consideration of the association of tumor and epididymo-orchitis, frequent and close follow up is suggested.

World Health Organization recommends a 45 day course of oral doxycycline $200 \mathrm{mg} /$ day and streptomycin 1 $\mathrm{g} /$ day IM for Brucellosis treatment. An alternative is a 45 day course of oral rifampicin $15 \mathrm{mg} / \mathrm{kg} /$ day $(600-800$ $\mathrm{mg}$ ) and doxycycline $200 \mathrm{mg} /$ day (11). In cases unresponsive to medical treatment orchiectomy is practiced. Afsar et al. reported 2 cases requiring orchiectomy in a 13 cases study with doxycycline and rifampicin treatment (12).

In conclusion, Brucella epididymo-orchitis must be kept in mind in the differential diagnosis of acute scrotum and epididmo-orchitis in Brusella-endemic countries.

\section{REFERENCES}

1. Mesner O, Riesenberg K, Biliar N, et al. The many faces of human-to-human transmission of brucellosis: congenital infection and outbreak of nosocomial disease related to an unrecognized clinical case Clin Infect Dis. 2007; 45:135-140.

2. Pappas G, Papadimitriou P, Akritidis N, et al. The new global map of human brucellosis. Lancet Infect Dis. 2006; 6:91-99.

3. Young EJ. Brucella species. In Mandell GL, Dolin R, Bennett JE (eds) Mandell, Douglas, and Bennett's Principles and Practice of Infectious Diseases 6th ed., Churchill Livingstone, Philadelphia 2005; pp 2669-2674.

4. Doganay M, Alp E. Brucellosis. In Rakel RE, Bope ET (eds). Conn's Current Therapy, 2006.

5. Ibrahim AI, Awad R, Shetty SD, et al. Genitourinary complications of brucellosis. Br J Urol. 1988; 61:294-298.

6. Sözen TH. Bruselloz. In Topcu AW, Soyletir G, Doganay M (eds) Infeksiyon hastaliklan. 2.baskl. Istanbul: Nobel Tip Kitabevleri; 2002, pp 636-642.

7. Canda AE, Akay O, Gürkan L, et al. Brucella Epididimoorsiti: Agr bölgesinde saptanan 4 olgunun sunumu. Türkiye Ekopatoloji Dergisi. 2006; 12:17-21.

8. Mert A, Ozaras R, Tabak F, et al. The sensitivity and specificity of Brucella agglutination tests. Diagn Microbiol Infect Dis. 2003; 46:241-243.

9. Colmenero JD, Munoz-Roca NL, Bermudez P, et al. Clinical findings, diagnostic approach, and outcome of Brucella melitensis epididymo-orchitis. Diagn Microbiol Infect Dis. 2007; 57:367-372.

10. Memish ZA, Venkatesh S. Brucellar epididymo-orchitis in Saudi Arabia: a retrospective study of 26 cases and review of the literature. BJU Int. 2001; 88:72-76.

11. Brucellosis in human and animals. Geneva (Switzerland): World Health Organization; 2006.

12. Afsar H, Baydar I, Sirmatel F: Epididymoorchitis due to brucellosis, Br J Urol. 1993; 72:104-105.

\section{Correspondence}

Aydemir Huseyin, MD

Department of Urology, Ministry of Health Sakarya Teaching and Research Hospital, Sakarya, Turkey

Gokcen Budak, MD

Department of Infectious Disease Clinic, Tire State Hospital Sakarya, Turkey

Salih Budak, MD (Corresponding Author)

salihbudak1977@gmail.com

Orcun Celik, MD

Okan Yalbuzdag, MD

Tepecik Educational and Research Hospital, Department of Urology

35140 Izmir, Turkey

İbrahim Keles, $M D$

Department of Urology, School of Medicine, Afyon Kocatepe University Afyonkarahisar, Turkey 